\title{
Article
}

\section{Testing the Children: Do Non-Genetic Health-Care Providers Differ in Their Decision to Advise Genetic Presymptomatic Testing on Minors? A Cross-Sectional Study in Five Countries in the European Union}

Plass, Anne Marie C., Baars, Marieke J.H., Cornel, Martina C., JulianReynier, Claire, Nippert, Irmgard, Harris, Hillary, Kristoffersson, Ulf, Schmidtke, Jörg, Anionwu, Elizabeth N., Benjamin, Caroline, Challen, Kirsty, Harris, Rodney and ten Kate, Leo P.

Available at http://clok.uclan.ac.uk/8241/

Plass, Anne Marie C., Baars, Marieke J.H., Cornel, Martina C., Julian-Reynier, Claire, Nippert, Irmgard, Harris, Hillary, Kristoffersson, Ulf, Schmidtke, Jörg, Anionwu, Elizabeth N. et al (2009) Testing the Children: Do Non-Genetic Health-Care Providers Differ in Their Decision to Advise Genetic Presymptomatic Testing on Minors? A Cross-Sectional Study in Five Countries in the European Union. Genetic Testing and Molecular Biomarkers, 13 (3). pp. 367-376. ISSN 1945-0265

It is advisable to refer to the publisher's version if you intend to cite from the work. http://dx.doi.org/10.1089/gtmb.2008.0119

For more information about UCLan's research in this area go to http://www.uclan.ac.uk/researchgroups/ and search for <name of research Group>.

For information about Research generally at UCLan please go to http://www.uclan.ac.uk/research/

All outputs in CLoK are protected by Intellectual Property Rights law, including

CLoK

Central Lancashire online Knowledge www.clok.uclan.ac.uk

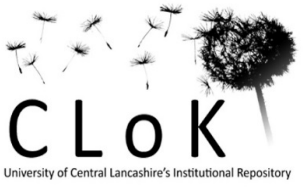




\section{CLoK}

Central Lancashire online Knowledge www.clok.uclan.ac.uk 
Plass, A.M.C., Baars, M.J.H., Cornel, M.C., Julian-Reynier, C., Nippert, I., Harris, H.,

Kristoffersson, U., Schmidtke, J., Anionwu, E.N., Benjamin, C., Challen, K., Harris, R., Kate, L.P, ten. Testing the children: do non-genetic health-care providers differ in their decision to advise genetic presymptomatic testing on minors? A cross-sectional study in five countries in the European Union. Genetic Testing and Molecular Biomarkers: 2009, 13(3), 367-376

\begin{tabular}{l|l} 
Postprint Version & 1.0 \\
\hline Journal website & $\underline{\text { http://online.liebertpub.com/doi/abs/10.1089/gtmb.2008.0119 }}$ \\
\hline Pubmed link & http://www.ncbi.nlm.nih.gov/pubmed/19473081 \\
DOI & $10.1089 /$ gtmb.2008.0119
\end{tabular}

This is a NIVEL certified Post Print, more info at http://www.nivel.eu

\section{Testing the Children: Do Non-Genetic Health-Care Providers Differ in Their Decision to Advise Genetic Presymptomatic Testing on Minors? A Cross-Sectional Study in Five Countries in the European Union}

Anne Marie C. Plass, ${ }^{1,2}$ MarieKe J.H. BaARs, ${ }^{3}$ Martina C. Cornel, ${ }^{1,2}$ Claire JulianREYNIER, ${ }^{4-6}$ IRMGARD NiPPERT, ${ }^{7}$ HILlARY HARRIS, ${ }^{8}$ UlF KRISTOFFERSSON, ${ }^{9}$ JO“ RG

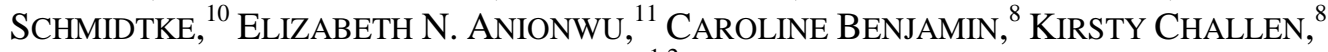
RODNEY HARRIS, AND LEO P. TEN KATE ${ }^{1,2}$

Background: Within Europe many guidelines exist regarding the genetic testing of minors. Predictive and presymptomatic genetic testing of minors is recommended for disorders for which medical intervention= preventive measures exist, and for which early detection improves future medical health. Aim: This study, which is part of the larger 5th EU-framework "genetic education" (GenEd) study, aimed to evaluate the self-reported responses of nongenetic health-care providers in five different EU countries (Germany, France, Sweden, the United Kingdom, and the Netherlands) when confronted with a parent requesting presymptomatic testing on a minor child for a treatable disease. Methods: A cross-sectional study design using postal, structured scenariobased questionnaires that were sent to 8129 general practitioners (GPs) and pediatricians, between July 2004 and October 2004, addressing selfreported management of a genetic case for which early medical intervention during childhood is beneficial, involving a minor. Results: Most practitioners agreed on testing the oldest child, aged 12 years (81.5\% for GPs and $87.2 \%$ for pediatricians), and not testing the youngest child, aged 6 months (72.6\% for GPs and $61.3 \%$ for pediatricians). After multivariate adjustment there were statistical differences between countries in recommending a genetic test for the child at the age of 8 years. Pediatricians in France (50\%) and Germany (58\%) would recommend a test, whereas in the United Kingdom (22\%), Sweden (30\%), and the Netherlands (32\%) they would not. Conclusion: Even though presymptomatic genetic testing in minors is recommended for disorders for which medical intervention exists, EU physicians are uncertain at what age starting to do so in young children. 
Plass, A.M.C., Baars, M.J.H., Cornel, M.C., Julian-Reynier, C., Nippert, I., Harris, H., Kristoffersson, U., Schmidtke, J., Anionwu, E.N., Benjamin, C., Challen, K., Harris, R., Kate, L.P ten. Testing the children: do non-genetic health-care providers differ in their decision to advise genetic presymptomatic testing on minors? A cross-sectional study in five countries in the European Union. Genetic Testing and Molecular Biomarkers: 2009, 13(3), 367-376

\section{INTRODUCTION}

Genetic testing of minors is a delicate matter and therefore treated with even more caution than adult genetic testing. Within Europe there is no common policy with regard to genetic testing of minors. Genetic testing of minors can be divided into three categories: symptomatic diagnostic testing, predictive and presymptomatic diagnostic testing, and carrier testing.

Symptomatic diagnostic testing is done to diagnose a specific disorder in an individual and is generally recommended as part of routine medical care since health improves with treatment or early diagnosis (e.g., genetic testing for cystic fibrosis). Still, once a diagnosis is made, this has implications not only for the affected child, but also for the parents, and other relatives in terms of recurrence risk. In contrast to symptomatic diagnostic genetic testing, carrier testing is not recommended during childhood (Borry et al., 2005). Ideally, it should be deferred until the child him- or herself is able to give proper informed consent. National legal regulations differ in regard to the question when a child has the full right to give his or her autonomous consent (De Lourdes et al., 2003), but usually this is not before the age of 18. Between the existing guidelines there is some disagreement on the role of the parents, psychological benefit, and release of information. Further, it is not clear whether postponing carrier testing is always in the child's best interest (Wertz et al., 1994; Clarke and Flinter, 1996). It is known that the majority of both carrier and noncarrier women in relation to X-linked severe combined immunodeficiency retrospectively reported that they wished they had been tested before the age of 18 to provide time to develop positive coping mechanisms and to adjust reproductive planning (Fanos et al., 2001). Predictive and presymptomatic genetic testing provides at-risk individuals with the opportunity to learn whether or not they have inherited a deleterious gene that will cause a health problem later in life, inevitably (presymptomatic) or with a substantially increased risk (predictive testing). Borry et al. (2006b) retrieved 27 guidelines and position papers that explicitly addressed predictive and presymptomatic genetic testing of minors in general (not disease specific), and were written in English (originally, or translated into English by the guideline developers). There were 14 guidelines from Europe (the United Kingdom [4], Germany [3], France [2], Italy, Switzerland, Belgium, and Denmark), including one EU guideline (European Societies of Human Genetics, 2006).

Presymptomatic genetic testing in minors is recommended only for childhood onset disorders for which medical intervention or preventive measures exists, and in which early detection improves future medical health (Ross and Moon, 2000; Borry et al., $2005,2006 \mathrm{~b})$. The age at which such testing should occur is dependent upon the age at which the child is likely to benefit from early medical intervention; this differs between disorders. Familial adenomatous polyposis (FAP) is one such genetic disorder. Clinical geneticists recommend presymptomatic genetic testing of minors for FAP. Those who carry the affected gene should be screened (by sigmoidoscopy) every 1-2 years beginning at the age of 10-12 years (Burt, 2000). Another such disease is hypertrophic cardiomyopathy (HCM), for which early medical intervention for those who carry the mutated gene also is recommended from the age of 10-12 years (Maron et al., 2003).

In the absence of clear medical benefit there was some disagreement between guidelines on whether or not the child should be tested in its own best interest. Some 
Plass, A.M.C., Baars, M.J.H., Cornel, M.C., Julian-Reynier, C., Nippert, I., Harris, H., Kristoffersson, U., Schmidtke, J., Anionwu, E.N., Benjamin, C., Challen, K., Harris, R., Kate, L.P, ten. Testing the children: do non-genetic health-care providers differ in their decision to advise genetic presymptomatic testing on minors? A cross-sectional study in five countries in the European Union. Genetic Testing and Molecular Biomarkers: 2009, 13(3), 367-376

guidelines stated that testing should be postponed until the child was old enough to decide for him- or herself, but it was not clear at what age this could be expected. Other guidelines stated that the parents should know what is in the child's best interest (socially or psychologically). Further the concept of best interest itself remained unclear. Finally, there was some disagreement on testing for late-onset diseases (Borry et al., 2006b). However, presymptomatic genetic testing is not recommended for late-onset disorders for which no medical treatment is available (e.g., Huntington Disease) (Bloch and Hayden, 1990; McConkie-Rosell and Spiridigliozzi, 2004).

In summary, there appears to be a consensus about diagnostic genetic testing of minors, about postponing carrier testing if possible, and about predictive and presymptomatic testing in minors, which is recommended only in circumstances where a clear medical benefit to the child can be demonstrated (Ross and Moon, 2000; McConkie-Rosell and Spiridigliozzi, 2004; Borry et al., 2006a, 2006b). In spite of the high degree of consensus that exists regarding genetic testing of minors, there is still reason to doubt the usefulness of the existing guidelines in daily healthcare practice, even in situations where there is clear medical benefit for the child. It can be difficult to determine the timing for testing for childhood onset diseases, to determine the age at which the child is competent to decide for him- or herself, to determine psychological benefit or what is in the child's best interest. This study aims to explore how nongenetic health-care providers would react when confronted with a parent requesting presymptomatic genetic testing on a minor child for a treatable disease.

The present study is part of a larger 5th EU-framework study in which genetic education (GenEd) for nongenetic health-care providers was investigated in two phases: Phase I of the GenEd project has provided evidence of the current policies relating to GenEd initially across five European countries with input from another six countries (Challen et al., 2005, 2006; Harris et al., 2006; Henriksson and

Kristoffersson, 2006; Julian-Reynier and Arnaud, 2006; Plass et al., 2006; Schmidtke et al., 2006); Phase II aimed to clarify professional needs by consulting nongeneticist health professionals ( Julian-Reynier et al., 2008).

It is hoped to improve patient care by facilitating the appropriate use of genetic information within clinical practice. As a part of this study, we assessed the selfreported responses of nongenetic health-care providers (general practitioners [GPs] and pediatricians) in five different EU countries (France, Germany, theUnitedKingdom, Sweden, and theNetherlands), presenting them a scenario of a parent requesting presymptomatic genetic testing on a minor child for a treatable disease.

\section{METHODS}

\section{Design}

Postal, structured questionnaire using a cross-sectional study design was used. The questionnaire was developed in English by a multidisciplinary team from all five countries and piloted among English-speaking health professionals in the target groups. Piloting in each country was a two-step process. First, the final English version of the questionnaire was discussed with small samples of each group of 
Plass, A.M.C., Baars, M.J.H., Cornel, M.C., Julian-Reynier, C., Nippert, I., Harris, H., Kristoffersson, U., Schmidtke, J., Anionwu, E.N., Benjamin, C., Challen, K., Harris, R., Kate, L.P. ten. Testing the children: do non-genetic health-care providers differ in their decision to advise genetic presymptomatic testing on minors? A cross-sectional study in five countries in the European Union. Genetic Testing and Molecular Biomarkers: 2009, 13(3), 367-376

medical doctors (two or three doctors) in each country or with their representatives (Germany). At this stage corrections were carried out to better adapt the English version to every health-care system and to help to avoid genetic slang and misunderstandings. Second, after the translation process (translation and backtranslation) and for piloting of the national versions, two or three physicians per specialty in each country were asked to fill out the questionnaire and to make remarks during this process. At this stage the remarks made mainly concerned typographical errors and improved wording of the questions. After postpilot amendments, translation and back-translation was undertaken into the four nonEnglish languages to ensure consistency.

\section{Procedure and sample}

In the five countries (France, Germany, the United Kingdom, Sweden, and the Netherlands) questionnaires were sent that contained a scenario relating to a genetic condition (see Appendix). These were sent out to 4244 GPs and 3885 pediatricians between July 2004 and October 2004. Subsequent questions addressed practitioners' self-reported responses to the scenario. The scenarios differed for GPs and pediatricians, to make the scenarios more applicable in their practice. The clinical scenario was chosen as one that could have resonance for clinicians within the specialty, even if it was a condition seen rarely. The conditions identified were HCM for GPs and FAP for pediatricians, as they both represent diseases where early medical intervention could be suggested at around 10 years, but rarely before, raising the issue of treatability or prevention at a young age.

The samples were randomly selected in each country, except for the sample of pediatricians in the Netherlands and Sweden. The number of pediatricians in these countries was too small to select a sample; thus, questionnaires were sent to all Dutch and Swedish pediatricians.

A brief postal reminder was sent within 2 weeks, and a second reminder, including the questionnaire, was sent after 1 month. Respondents in France, Germany, Sweden, and the Netherlands were offered an incentive of 10 euros (\$14), and $£ 5(\$ 10)$ in the United Kingdom. In some countries the nonresponding GPs received a third reminder by mail (the United Kingdom) or phone (France) because of the lower response rate of GPs. For this reason the incentive for GPs was increased in the United Kingdom to $£ 10$ (\$20).

\section{Measures}

The questions that were asked regarding the scenarios presented were similar for GPs and pediatricians, and were posed separately for each child that was mentioned in the scenario. Thus, GPs had to answer the questions solely for Melanie (12 years) and Tom (6 months), whereas the pediatricians also had to consider Catherine (8 years). Respondents were asked to assume that a mutation had been discovered in the parent and were asked to rate their likelihood of testing Melanie, Tom, and Catherine (pediatricians only) on a four-point scale: definitely not, probably not, probably yes, or definitely yes. They were then asked to describe their reasoning for testing or not testing each child. The four-option tick boxes for testing (probably yes or definitely yes) were as follows: "I would test this child to plan early medical care”, “ "I would test this child to relieve its parent's uncertainty”; “'I would test this child since it is old enough to understand the implications"; "I would test this child for other 
Plass, A.M.C., Baars, M.J.H., Cornel, M.C., Julian-Reynier, C., Nippert, I., Harris, H., Kristoffersson, U., Schmidtke, J., Anionwu, E.N., Benjamin, C., Challen, K., Harris, R., Kate, L.P. ten. Testing the children: do non-genetic health-care providers differ in their decision to advise genetic presymptomatic testing on minors? A cross-sectional study in five countries in the European Union. Genetic Testing and Molecular Biomarkers: 2009, 13(3), 367-376

reasons.’' The three-option tick boxes for not testing (probably not or definitely not) were as follows: "I would not test this child as the child is too young to plan adequate medical care"; "I would not test this child as the child is not old enough to understand the implications"; " I would not test this child for other reasons." Unless otherwise stated, for each question, only one box could be ticked. Further, demographic variables were asked, for example, sex, age, and work experience. Data were entered by scanning using SNAP7 software with operator checking for negative answers and double-ticked answers.

\section{Analyses}

All analyses were performed using SPSS 12.0 for Windows.

To identify variables associated with the intention to test or not to test each child mentioned in the scenario, differences between the participating countries, specialties, sex, age categories ( $<50$ years vs. _50 years), and years of experience were tested using the $\mathrm{w}^{2}$-test for categorical data. Significance level was determined at $\mathrm{p}<0.05$. To adjust for covariance and confounding, variables with a $\mathrm{p}<0.1$ in univariate analysis were included in a multiple logistic regression analysis.

\section{RESULTS}

\section{Response rate}

In total, 8129 questionnaires were sent out to GPs and pediatricians in the five participating countries; 367 questionnaires were marked as not having reached their intended recipient (gone away, on leave, or wrong address); 2918 were completed and returned. (In Germany, because of a greater response rate than predicted, more questionnaires than in the other countries were received. Including the total number of received questionnaires in the data base would have resulted in a larger proportionate number of German pediatricians represented in the overall study population. This would influence overall outcomes of the total sample of pediatricians.

Therefore, it was decided to randomly exclude 385 German questionnaires.). Finally, 2533 were usable questionnaires (1176 GPs and 1357 pediatricians). Eight GPs and six pediatricians were then excluded as they were over the 70 years age criterion, leaving a dataset of 1168 GPs and 1351 pediatricians (see Table 1 for demographic variables of the study population).

The total response rate was 37\% (30\% for GPs and $46 \%$ for pediatricians). Representativeness of the sample on the basis of sex and age is shown in Table 1 (Calefato et al., 2008).

\section{Testing the children}

In all five countries respondents mainly agreed on testing Melanie and not testing Tom (see Table 2). There were significant differences between countries in preference for testing Melanie ( $\mathrm{w} 2=76.8 ; \mathrm{df}=4 ; \mathrm{p}<0.001)$, testing Catherine ( $\mathrm{w} 2=88.4 ; \mathrm{df}=4 ; \mathrm{p}<0.001$ ), and testing Tom (w2=41.7; $\mathrm{df}=4 ; \mathrm{p}<0.001)$ (see Table 2). It was significantly less likely for the GP or the pediatrician to test Melanie in the United Kingdom compared to the other countries (Germany odds ratio adjusted [ORadj] =4.0 [2.8-5.8]; France ORadj=2.7 [1.9-3.8]; the Netherlands ORadj=2.3 [1.6-3.2]; Sweden ORadj=2.2 [1.6-3.1]). For Tom, he was most likely to be tested in 
Plass, A.M.C., Baars, M.J.H., Cornel, M.C., Julian-Reynier, C., Nippert, I., Harris, H., Kristoffersson, U., Schmidtke, J., Anionwu, E.N., Benjamin, C., Challen, K., Harris, R., Kate, L.P ten. Testing the children: do non-genetic health-care providers differ in their decision to advise genetic presymptomatic testing on minors? A cross-sectional study in five countries in the European Union. Genetic Testing and Molecular Biomarkers: 2009, 13(3), 367-376

Germany compared to the other countries (Sweden ORadj=0.5 [0.4-0.6]; UK ORadj $=0.5$ [0.4-0.6]; the Netherlands ORadj= 0.7 [0.6-0.9]; France ORadj $=0.8$ [NS]); particularly, pediatricians in Germany were most in favor to test Tom (see Table 2).

In Germany the majority and in France practically half of the pediatricians were in favor of testing Catherine, whereas in the other countries (the Netherlands, Sweden, and the United Kingdom) the majority was in favor of not testing Catherine (see Table 2).

\section{[TABLE 1-2]}

When analyzing all countries together, there were significant differences between GPs and pediatricians, between men and women, and between older and younger physicians: GPs were less likely to test Melanie (ORadj 0.8 [0.8-0.9]) compared to pediatricians. Women were less likely to test Melanie (ORadj 0.8 [0.6-0.9]), but more likely to test Tom (ORadj 1.6 [1.3-1.9]) compared to men. Younger physicians (aged 24-50 years) were less likely to test Melanie, compared to their older colleagues (aged 51-84 years) (ORadj 0.7 [0.5-0.9]). No differences between specialties and age were found concerning testing Tom, or for age and sex concerning testing Catherine.

\section{Reasons for testing Melanie}

The most important reason to test Melanie (12 years) for both GPs and pediatricians in all countries was to plan early medical care (see Table 3 ). The reasons mentioned differed significantly between countries ( $\mathrm{w}^{2}=142.5$; $\mathrm{df}=12$; $\left.\mathrm{p}<0.001\right)$.

Most important reason not to test Melanie (12 years) was " none of the reasons mentioned." Various other reasons was ticked mostly in this case, except for the Dutch GPs and the pediatricians in the United Kingdom who ticked "The child is not old enough to understand the medical implications"' ( $\left.\mathrm{w}^{2}=20.8 ; \mathrm{df}=8 ; \mathrm{p}=0.008\right)$ (see Table 3). In ticking the category "other' the most often explanation mentioned for not testing Melanie was that the respondent felt that he or she should refer to someone else in the medical system in this case (see Table 4).

\section{Testing Tom}

The most important reason for both pediatricians and GPs to test Tom (6 months) in all five countries was to relieve his parents' uncertainty. The reasons mentioned for not testing Tom differed between countries $\left(\mathrm{w}^{2}=24.3 ; \mathrm{df}=8 ; \mathrm{p}<0.002\right)$ (see Table 5). The most important reason not to test Tom (6 months) for both pediatricians and GPs in Germany, the United Kingdom, Sweden, and France was the feeling that no medical treatment is required at this age. In the Netherlands both GPs and pediatricians felt that Tom should not be tested because the child is not old enough to understand the medical implications $\left(\mathrm{w}^{2}=150.0\right.$; $\mathrm{df}=8$; $\left.\mathrm{p}<0.001\right)$ (see Table 5).

\section{[TABLE 3]}

\section{Testing Catherine (pediatricians scenario only)}

Most important reason to test Catherine (8 years) in all five countries was to relieve her parents' uncertainty. The reasons that were mentioned for testing Catherine differed and were significantly associated with country $\left(\mathrm{w}^{2}=57.9 ; \mathrm{df}=8 ; \mathrm{p}<0.008\right)$ 
Plass, A.M.C., Baars, M.J.H., Cornel, M.C., Julian-Reynier, C., Nippert, I., Harris, H., Kristoffersson, U., Schmidtke, J., Anionwu, E.N., Benjamin, C., Challen, K., Harris, R., Kate, L.P. ten. Testing the children: do non-genetic health-care providers differ in their decision to advise genetic presymptomatic testing on minors? A cross-sectional study in five countries in the European Union. Genetic Testing and Molecular Biomarkers: 2009, 13(3), 367-376

(see Table 6). Most important reason not to test Catherine (8 years) $(n=374)$ for pediatricians in France, Germany, and Sweden was the feeling that no medical treatment is required at this age. In the Netherlands and the United Kingdom the most important reason not to test Catherine was the fact that she is not old enough to understand the medical implications $\left(\mathrm{w}^{2}=27.5 ; \mathrm{df}=8 ; \mathrm{p}=0.001\right)$ (see Table 6).

\section{DISCUSSION}

\section{[TABLE 4-5]}

In spite of the high degree of consensus stating that " genetic testing in children is recommended under circumstances where a clear medical benefit to the child can be demonstrated" 'that exists within the many guidelines regarding genetic testing of minors (Ross and Moon, 2000; McConkie- Rosell and Spiridigliozzi, 2004; Borry et al., 2005b, 2006), no such high degree of consensus in favor of testing could be retrieved from the self-reported answers of the participating GPs and pediatricians. Our data show that this is only upheld in clinical practice for testing the oldest child (Melanie aged 12 years). In particular, ambiguity exists on presymptomatic genetic testing of young children for diseases for which medical intervention is required at some time during childhood, but which is not yet required or available at the time of the request, because of the young age of the child.

\section{[TABLE 6]}

Overall, GPs and pediatricians in the five participating EU countries (France, Germany, the Netherlands, Sweden, and the United Kingdom) mainly agreed on testing Melanie aged 12 years and not testing Tom aged 6 months on their parent's request after a mutation was found in the parent. However, there were differences between countries. It was most likely in Germany and France that the children become tested on the request of their affected parent, independent of their age, and the least likely in the United Kingdom. Particularly, pediatricians in Germany were more often than German GPs and physicians in the other participating countries in favor of testing the youngest child Tom of 6 months.

There was a striking difference between countries concerning testing Catherine aged 8 years. Pediatricians in France and in Germany more frequently favored testing Catherine, whereas in the other countries pediatricians were mainly in favor of not testing Catherine. One could argue that the differences found might be due to the differences in medical care system of the participating countries. At the time of the survey, in the United Kingdom and the Netherlands, for some physicians, including pediatricians, the standard of care would be to refer to another physician who was a specialist on the basis of the so-called gatekeeper system in which patients have to consult a primary health-care provider before access to specialists within the medical care system can be obtained.

This might explain why these physicians more often ticked "no" if they were asked whether or not they were going to test the child mentioned in the questionnaire. They might have interpreted the question literally as if it were asked whether or not they themselves were going to test the child. Still, there were many physicians in these countries who justified their negative answer by ticking one of the reasons that were 
Plass, A.M.C., Baars, M.J.H., Cornel, M.C., Julian-Reynier, C., Nippert, I., Harris, H., Kristoffersson, U., Schmidtke, J., Anionwu, E.N., Benjamin, C., Challen, K., Harris, R., Kate, L.P. ten. Testing the children: do non-genetic health-care providers differ in their decision to advise genetic presymptomatic testing on minors? A cross-sectional study in five countries in the European Union. Genetic Testing and Molecular Biomarkers: 2009, 13(3), 367-376

already mentioned in the questionnaire (the child is not old enough to understand the medical implications; no medical treatment is required at this age). Thus, it remains unclear why physicians in France and Germany seemingly act more in line with the idea of medical benefit regardless its start point, which is mentioned in some of the existing EU guidelines (Borry, et al., 2006b), whereas physicians in Sweden, the Netherlands, and the United Kingdom seem to act more in line with several American and a Swiss guideline stating that genetic testing in minors for childhoodonset diseases (regardless of treatment possibilities-AP) is recommended when the results are of “immediate”' relevance for a child's health (Borry et al., 2005a). Further, the latter might have planned to advise the parents to return to the clinic with the child at a later stage, to test the child at the age from which medical intervention actually is needed. However, this was not asked in the questionnaire.

The reasons that were indicated by the participating physicians for or against testing each child questioned were also associated with each country. Particularly, the reasons for not testing the children differed between countries. Physicians agreed on testing Melanie to plan early medical care and Tom and Catherine to relieve their parents' uncertainty, but they were less in agreement in justifying their negative answers. In some cases physicians in the Netherlands, Sweden, and the United Kingdom differed from those in the other countries; moreover, in some cases GPs differed from pediatricians.

Especially in the case of the oldest child (Melanie aged 12 years) various reasons were stated why this child should not be tested: lack of knowledge, psychological harm, ethical issues, and impact to the family, among others, were brought up in justifying the negative decision. Thus, in being uncertain and lacking knowledge about common practice when confronted with an affected parent requesting presymptomatic genetic testing on a minor child for a treatable disease, the request will be turned down, and important preventive treatment possibilities might be wasted. Apparently, reasons for not testing a child are less straightforward. This might even be more so in a situation where one is aware that one should have acted otherwise, since analogous to that it was found that clinicians brought up several nonmedical reasons in offering predictive testing in young people for late-onset disorders, whereas they knew that this was not recommended (Duncan et al., 2005). Similar to the findings of Baars et al. (2007), who found that GPs were more reserved concerning genetic testing in general compared to pediatricians, GPs were found to be most reserved in testing the children compared to the participating pediatricians. This again might be due to the medical gatekeeper system in some of the participating countries: in those countries GPs would refer further into the medical system rather than testing the child personally. However, it must be taken into account that in this study the GPs and pediatricians were not presented with the same scenario and therefore a true comparison cannot be made. Still, since both diseases are equal in their need for early medical intervention we feel that comparing GPs and pediatricians at this point is permitted (Burt, 2000; Maron et al., 2003). Further, there were differences between male and female physicians and older and younger physicians. The older physicians were more often in favor of testing the children.

This is consistent with the finding elsewhere that older, and more experienced GPs, gynecologists=obstetricians, and pediatricians were most innovative in offering 
Plass, A.M.C., Baars, M.J.H., Cornel, M.C., Julian-Reynier, C., Nippert, I., Harris, H., Kristoffersson, U., Schmidtke, J., Anionwu, E.N., Benjamin, C., Challen, K., Harris, R., Kate, L.P, ten. Testing the children: do non-genetic health-care providers differ in their decision to advise genetic presymptomatic testing on minors? A cross-sectional study in five countries in the European Union. Genetic Testing and Molecular Biomarkers: 2009, 13(3), 367-376

genetic testing (Baars et al., 2007). There was a remarkable difference within the group women and their preference for testing Melanie and Tom. Contrary to male physicians they were more in favor of testing Tom and less in favor of testing Melanie. We cannot think of any plausible explanation why this occurred. Moreover, no differences between male and female students were found in a study in which students' decision on whether or not to genetically test a minor was being examined (Riordan and Loescher, 2006). This decision did depend on the disease presented, on the age of the minor, but also on the amount of GenEd the students had had during their years of education: the more GenEd, the less prone they were to test the youngest child (at the age of 7), but sex differences did not occur.

Despite the large number of physicians that were found to be in favor of testing at least one of the children, these findings are still not in line with the general recommendation that children should undergo presymptomatic diagnostic genetic testing if the disorder concerned is treatable and early medical intervention desirable. However, it can be discussed whether or not it should be recommended to test Tom already at the age of 6 months, since medical treatment is not required at his age for both FAP and HCM. Testing Tom could be postponed till the time medical treatment is required. More clarity of when this time has come and thus a clear definition of the age at which genetic presymptomatic testing of the child ideally should be carried out, preferably related to specific diseases, is therefore needed. One might even consider stressing the medical benefits in cases of presymptomatic testing of minors for a treatable disease, over psychological benefit (or harm).

More in general, it could be recommended that minors should not be tested before medical intervention (see also www .eshg.org for proposed recommendations on this issue). This might facilitate the utility of the existing guidelines in daily health-care practice and optimize patient care. The balance between the psychological benefits or harm should strongly be considered in cases of genetic testing for nontreatable diseases or when carrier testing is concerned.

\section{Limitations of the study}

In some of the participating countries the GPs do have the role of gatekeeper; in other countries they do not. Due to these differences in health-care systems, some physicians might have interpreted the question literally that was posed about testing the child.

The scenario that was presented in the questionnaire was more applicable to GPs and pediatricians in some countries compared to others. In those countries were it was difficult for physicians to imagine that this problem would be presented to them in their daily practice, they might have decided more negatively than they otherwise would have.

To not lose comparability of the data gathered between countries and specialties, and to achieve a representative sample based on power analysis, it was decided only to include the first 250 filled-out questionnaires returned for each specialty in each country. In some countries or with regard to some specialties, particularly primary health care, it is known that it is difficult to achieve high response rates (Robertson et al., 2005; Keating et al., 2008). The response rate of for pediatricians is slightly below average in large studies, but that of GPs is low (Robertson et al., 2005). Nevertheless, we feel that this is a useful sample. Moreover, there is no necessary 
Plass, A.M.C., Baars, M.J.H., Cornel, M.C., Julian-Reynier, C., Nippert, I., Harris, H., Kristoffersson, U., Schmidtke, J., Anionwu, E.N., Benjamin, C., Challen, K., Harris, R., Kate, L.P ten. Testing the children: do non-genetic health-care providers differ in their decision to advise genetic presymptomatic testing on minors? A cross-sectional study in five countries in the European Union. Genetic Testing and Molecular Biomarkers: 2009, 13(3), 367-376

relationship between response rate and bias: surveys with low response rates might provide a representative sample of the population of interest (Robertson et al., 2005). Finally, the study findings in some areas could be biased to physicians who hold more extreme views or who were interested in the subject of genetics.

\section{CONCLUSION}

It is of great importance to formulate a standard unambiguous guideline on genetic testing on minors, within the European Union, to create more clarity on when children should be tested for treatable diseases: immediately, regardless of age, or should it be postponed until the age at which medical intervention is actual available, to plan early medical care. This will optimize patient care and prevent important preventive treatment possibilities from being wasted.

\section{Acknowledgment}

This study was funded by the European Community 5th Framework Programme.

\section{Disclosure Statement}

No competing financial interests exist.

\section{REFERENCES}

Baars MJH, Henneman L, Plass AMC, et al. (2007) Beliefs and self-perceived competence of general practitioners, gynaecologists and paediatricians with regard to genetic testing. In: Baars MJH (ed) Genetic Knowledge, Opinions and Self- Perceived Competence of NonGenetic Health Care Providers. Imprimo, Bussum, pp 41-62.

Bloch M, Hayden MR (1990) Opinion: predictive testing for Huntington disease in childhood: challenges and implications. Am J Hum Genet 46:1-4.

Borry P, Fryns JP, Schotsmans P, et al. (2005) Attitudes towards carrier testing in minors: a systematic review. Genet Couns 16:341-352.

Borry P, Fryns JP, Schotsmans P, et al. (2006a) Carrier testing in minors: a systematic review of guidelines and position papers. Eur J Hum Genet 14(2):133-138. Review.

Borry P, Stultiens L, Nys H, et al. (2006b) Presymptomatic and predictive genetic testing in minors: a systematic review of guidelines and position papers. Clin Genet 70:374-381.

Burt RW (2000) Colon cancer screening. Gastroenterology 119: 837-853.

Calefato JM, Nippert I, Harris HJ, et al. (2008) Assessing educational priorities in genetics for general practitioners and specialists in five countries: factor structure of the GeneticEducational Priorities (Gen-EP) scale. Genet Med 10:99-106.

Challen K, Harris HJ, Julian-Reynier C, et al. (2005) Genetic education and nongenetic health professionals: educational providers and curricula in Europe. Genet Med 7:302-310. Challen K, Harris H, Benjamin CM, et al. (2006) Genetics teaching for non-geneticist health care professionals in the UK. Community Genet 9:251-259.

Clarke A, Flinter F (1996) The genetic testing of children: a clinical perspective. In: Marteau TM, Richards MP (eds) The Troubled Helix: Social and Psychological Implications of the NewHuman Genetics.CambridgeUniversity Press, Cambridge, pp 164-176.

De Lourdes LM, Larcher V, Kurz R (2003) Informed consent= assent in children. Statement of the Ethics Working Group of the Confederation of European Specialists in Paediatrics (CESP). Eur J Pediatr 162:629-633.

Duncan RE, Savulescu J, Gillam L, et al. (2005) An international survey of predictive genetic testing in children for adult onset conditions. Genet Med 7:390-396.

European Societies of Human Genetics (2006) Provision of genetic services in Europecurrent practices and issues: recommendations of the European Societies of Human Genetics. Eur J Hum Genet 11:s2-s4. 
Plass, A.M.C., Baars, M.J.H., Cornel, M.C., Julian-Reynier, C., Nippert, I., Harris, H., Kristoffersson, U., Schmidtke, J., Anionwu, E.N., Benjamin, C., Challen, K., Harris, R., Kate, L.P ten. Testing the children: do non-genetic health-care providers differ in their decision to advise genetic presymptomatic testing on minors? A cross-sectional study in five countries in the European Union. Genetic Testing and Molecular Biomarkers: 2009, 13(3), 367-376

Fanos JH, Davis J, Puck JM (2001) Sib understanding of genetics and attitudes toward carrier testing for X-linked severe combined immunodeficiency. Am J Med Genet 98:46-56.

Harris R, Challen K, Benjamin C, et al. (2006) Genetic education for non-geneticist health professionals. Community Genet 9:224-226.

Henriksson K, Kristoffersson U (2006) Education in medical genetics for non-genetic health care providers in Sweden. Community Genet 9:240-245.

Julian-Reynier C, Arnaud S (2006) France: genetics education for non-genetics health care providers. Community Genet 9:227- 234.

Julian-Reynier C, Nippert I, Celefato JM, et al. (2008) Genetics in clinical practice: general practitioners' educational priorities in European countries. Genet Med 10:107-113.

Keating NL, Zaslavsky AM, Goldstein J, et al. (2008) Randomized trial of $\$ 20$ versus $\$ 50$ incentives to increase physician survey response rates. Med Care 46:878-881.

Maron BJ, McKenna WJ, Danielson GK, et al. (2003) American College of Cardiology=European Society of Cardiology Clinical Expert Consensus Document on Hypertrophic Cardiomyopathy.

A report of the American College of Cardiology Foundation Task Force on Clinical Expert Consensus Documents and the European Society of Cardiology Committee for Practice Guidelines. Eur Heart J 24:1965-1991.

McConkie-Rosell A, Spiridigliozzi GA (2004) "Family matters": a conceptual framework for genetic testing in children. J Genet Couns 13:9-29.

Plass AM, Baars MJ, Beemer FA, et al. (2006) Genetics education for non-genetic health care professionals in the Netherlands (2002). Community Genet 9:246-250.

Riordan SH, Loescher LJ (2006) Medical students' attitudes toward genetic testing of minors. Genet Test 10:68-73.

Robertson J, Walkom EJ, McGettigan P (2005) Response rates and representativeness: a lottery incentive improves physician survey return rates. Pharmacoepidemiol Drug Saf 14: 571-577.

Ross LF, Moon MR (2000) Ethical issues in genetic testing of children. Arch Pediatr Adolesc Med 154:873-879.

Schmidtke J, Paul Y, Nippert I (2006) Education in medical genetics for physicians: Germany. Community Genet 9:235-239.

Wertz DC, Fanos JH, Reilly PR (1994) Genetic testing for children and adolescents. Who decides? JAMA 272:875-881.

\section{APPENDIX: SCENARIOS}

\section{GP scenario: sudden death}

Mr. Smith (aged 35 years) attends your surgery because his 27-year-old brother, a competitive swimmer, has just died suddenly. He collapsed in the pool and died despite defibrillation.

Although sudden death might not immediately suggest a genetic condition, Mr. Smith is worried because his mother's sister died suddenly aged 30 years and asks whether the same may happen to him or his children Melanie (12 years) and Tom (6 months).

He has been told that his brother's postmortem demonstrated hypertrophic cardiomyopathy, which can be inherited as an autosomal dominant condition. Eighty percent of nontraumatic sudden deaths in young athletes are due to inherited or congenital cardiovascular abnormalities, and hypertrophic cardiomyopathy accounts for $40-50 \%$ of these. Genetic testing may lead to identification of patients at high risk for sudden death as early as 10 years of age. Treatment can be considered with medication or implantable defibrillators. 
Plass, A.M.C., Baars, M.J.H., Cornel, M.C., Julian-Reynier, C., Nippert, I., Harris, H.,

Kristoffersson, U., Schmidtke, J., Anionwu, E.N., Benjamin, C., Challen, K., Harris, R., Kate, L.P. ten. Testing the children: do non-genetic health-care providers differ in their decision to advise genetic presymptomatic testing on minors? A cross-sectional study in five countries in the European Union. Genetic Testing and Molecular Biomarkers: 2009, 13(3), 367-376

\section{Pediatric scenario: familial adenomatous polyposis scenario}

Mrs. Ogilvie (aged 31 years), a mother of three children, Melanie (12 years), Catherine (8 years), and Tom (6 months), attends your clinic. Mrs. Ogilvie has a family history of colon cancer. Her father died at 42 years of age with colon cancer (no histology report available). Mrs. Ogilvie recently had a colectomy when she presented with rectal bleeding shortly after Tom's birth. The presence of hundreds of polyps was consistent with a diagnosis of typical familial adenomatous polyposis, an autosomal dominant condition.

She has been discharged from surgical services. Mrs.

Ogilvie has come to terms with the diagnosis, but she is now worried about the genetic risk for her children. If a gene mutation for typical familial adenomatous polyposis can be found in Mrs. Ogilvie's family, presymptomatic testing will be possible. Polyps can appear in the bowel between 12 and 25 years of age. It is very unusual to develop colon cancer as early as 8 years. 
Plass, A.M.C., Baars, M.J.H., Cornel, M.C., Julian-Reynier, C., Nippert, I., Harris, H.,

Kristoffersson, U., Schmidtke, J., Anionwu, E.N., Benjamin, C., Challen, K., Harris, R., Kate, L.P. ten. Testing the children: do non-genetic health-care providers differ in their decision to advise genetic presymptomatic testing on minors? A cross-sectional study in five countries in the European Union. Genetic Testing and Molecular Biomarkers: 2009, 13(3), 367-376

\section{TABLES}

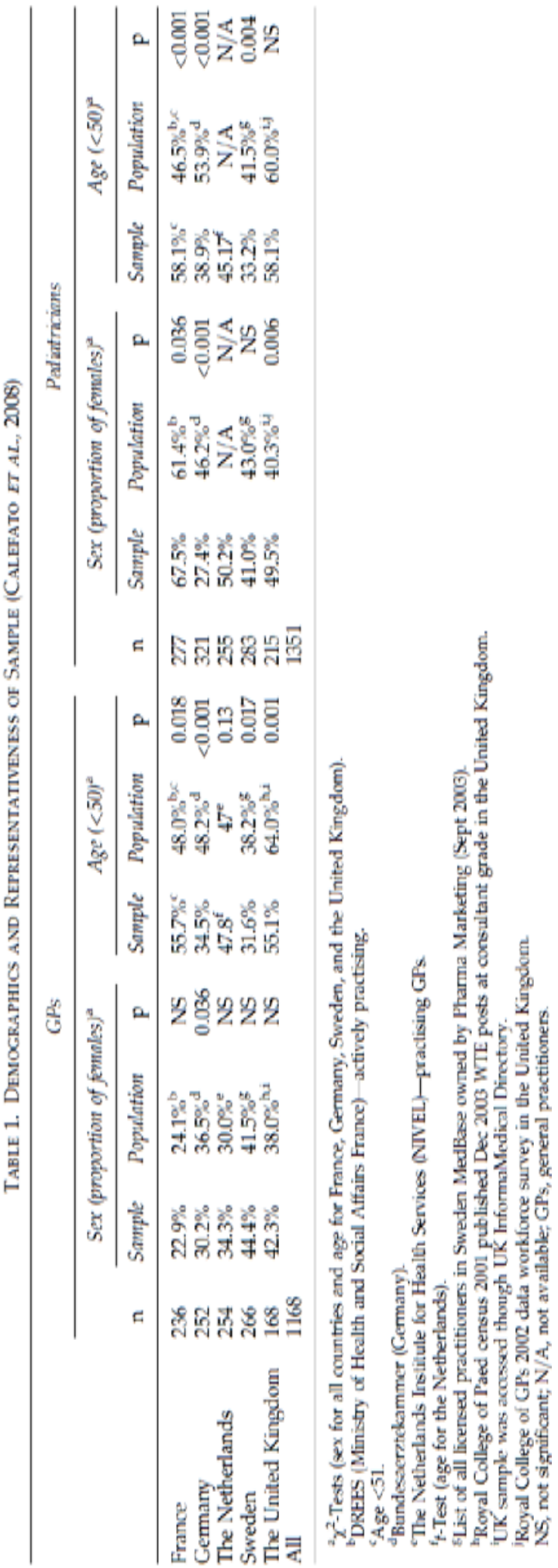


Plass, A.M.C., Baars, M.J.H., Cornel, M.C., Julian-Reynier, C., Nippert, I., Harris, H.,

Kristoffersson, U., Schmidtke, J., Anionwu, E.N., Benjamin, C., Challen, K., Harris, R., Kate, L.P. ten. Testing the children: do non-genetic health-care providers differ in their decision to advise genetic presymptomatic testing on minors? A cross-sectional study in five countries in the European Union. Genetic Testing and Molecular Biomarkers: 2009, 13(3), 367-376

Table 2. Percentages of GPs and Pediatricians in Favor of Testing the Children Mentioned in the Scenario That Was Presented to Them Divided Over the Five Participating Countries

\begin{tabular}{lrccc}
\hline GPs & $\mathrm{n}$ & Test Melanie & Test Tom \\
\hline France & 236 & $84.7 \%$ & $32.6 \%$ \\
Germany & 252 & $89.7 \%$ & $31.0 \%$ \\
The Netherlands & 254 & $79.7 \%$ & $33.5 \%$ \\
Sweden & 266 & $80.1 \%$ & $22.6 \%$ \\
The United Kingdom & 168 & $70.1 \%$ & $20.2 \%$ \\
All & 1168 & $81.5 \%$ & $28.4 \%$ \\
\hline \multicolumn{5}{c}{ Test } \\
Pediatricians & $\mathrm{n}$ & Melanie & Test Tom & Catherine \\
\hline France & 277 & $88.8 \%$ & $31.8 \%$ & $49.5 \%$ \\
Germany & 321 & $92.2 \%$ & $42.4 \%$ & $57.9 \%$ \\
The Netherlands & 255 & $90.6 \%$ & $26.7 \%$ & $32.2 \%$ \\
Sweden & 283 & $88.9 \%$ & $22.5 \%$ & $29.8 \%$ \\
The United Kingdom & 215 & $71.2 \%$ & $23.7 \%$ & $22.3 \%$ \\
All & 1351 & $87.2 \%$ & $30.1 \%$ & $39.7 \%$ \\
\hline
\end{tabular}

colleagues (aged 51-84 years) (ORadj 0.7 [0.5-0.9]). No differences between specialties and age were found concerning testing Tom, or for age and sex concerning testing Catherine. 
Plass, A.M.C., Baars, M.J.H., Cornel, M.C., Julian-Reynier, C., Nippert, I., Harris, H.,

Kristoffersson, U., Schmidtke, J., Anionwu, E.N., Benjamin, C., Challen, K., Harris, R., Kate, L.P. ten. Testing the children: do non-genetic health-care providers differ in their decision to advise genetic presymptomatic testing on minors? A cross-sectional study in five countries in the European Union. Genetic Testing and Molecular Biomarkers: 2009, 13(3), 367-376

Table 3. Most Important Reasons Mentioned by Responding GPs and Pediatricians for Testing or Not Testing Melanie Per Country

\begin{tabular}{|c|c|c|}
\hline GPs & & $\%$ \\
\hline \multicolumn{3}{|c|}{ Most important reason to test Melanie (12 years) $(\mathrm{n}=958)$} \\
\hline France & To plan early medical care & 42.0 \\
\hline Germany & To plan early medical care & 43.8 \\
\hline The Netherlands & To plan early medical care & 46.3 \\
\hline Sweden & To plan early medical care & 62.9 \\
\hline The United Kingdom & To plan early medical care & 54.2 \\
\hline \multicolumn{3}{|c|}{ Most important reason not to test Melanie $(12$ years $)(n=213)$} \\
\hline France & Various other reasons & 75.0 \\
\hline Germany & Various other reasons & 57.7 \\
\hline The Netherlands & $\begin{array}{l}\text { The child is not old enough to understand } \\
\text { the medical implications }\end{array}$ & 50.8 \\
\hline Sweden & Various other reasons & 63.0 \\
\hline The United Kingdom & Various other reasons & 65.4 \\
\hline Pediatricians & & $\%$ \\
\hline \multicolumn{3}{|c|}{ Most important reason to test Melanie $(12$ years $)(\mathrm{n}=1183)$} \\
\hline France & To plan early medical care & 42.7 \\
\hline Germany & To plan early medical care & 45.3 \\
\hline The Netherlands & To plan early medical care & 58.4 \\
\hline Sweden & To plan early medical care & 71.2 \\
\hline The United Kingdom & To plan early medical care & 59.5 \\
\hline \multicolumn{3}{|c|}{ Most important reason not to test Melanie (12 years) $(\mathrm{n}=145)$} \\
\hline France & Various other reasons & 44.0 \\
\hline Germany & Various other reasons & 52.4 \\
\hline The Netherlands & Various other reasons & 55.0 \\
\hline Sweden & Various other reasons & 36.7 \\
\hline The United Kingdom & $\begin{array}{l}\text { The child is not old enough to } \\
\text { understand the medical implications }\end{array}$ & 46.9 \\
\hline
\end{tabular}

Table 4. Overview of Reasons That Were Mentioned When Physicians Ticked "Other" in Answering the Question Whether or Not to Test Melanie Negatively, Divided into 12 Main Categories

Main categories of reasons mentioned not to test Melanie

Number of times this reason was mentioned

I am not able to test the child personally (referral further in the medical system is needed: to a geneticist or to the hospital to have the blood test taken)

I do not have enough knowledge about this matter or about the correct practice

The child itself should decide (not the parent)

Because of ethical problems; consequences for family members

Because of (severe) psychological or emotional harm

Because of insurance or financial consequences

It should be discussed with both parents (not solely on the request of one parent)

Wait until after puberty or legal age

There is no medical treatment available

I am not sure that the child is old enough to understand

Advise a physical examination instead of a genetic test, or an alternative therapy

Wait until there are symptoms of the disease

Impossible to read

Total

Some respondents mentioned more than one reason. 
Plass, A.M.C., Baars, M.J.H., Cornel, M.C., Julian-Reynier, C., Nippert, I., Harris, H., Kristoffersson, U., Schmidtke, J., Anionwu, E.N., Benjamin, C., Challen, K., Harris, R., Kate, L.P. ten. Testing the children: do non-genetic health-care providers differ in their decision to advise genetic presymptomatic testing on minors? A cross-sectional study in five countries in the European Union. Genetic Testing and Molecular Biomarkers: 2009, 13(3), 367-376

Table 5. Most Important Reasons Mentioned by Responding GPs and Pediatricians for Testing or Not Testing Tom Per Country

\begin{tabular}{|c|c|c|}
\hline GPS & & $\%$ \\
\hline \multicolumn{3}{|c|}{ Most important reason to test Tom $(6$ months $)(\mathrm{n}=334)$} \\
\hline France & To relieve his parents uncertainty & 89.6 \\
\hline Germany & To relieve his parents uncertainty & 88.5 \\
\hline The Netherlands & To relieve his parents uncertainty & 89.4 \\
\hline Sweden & To relieve his parents uncertainty & 95.0 \\
\hline The United Kingdom & To relieve his parents uncertainty & 73.5 \\
\hline \multicolumn{3}{|c|}{ Most important reason not to test Tom $(6$ months $)(\mathrm{n}=596)$} \\
\hline France & No medical treatment is required at this age & 75.2 \\
\hline Germany & No medical treatment is required at this age & 73.0 \\
\hline The Netherlands & $\begin{array}{l}\text { The child is not old enough to understand } \\
\text { the medical implications }\end{array}$ & 37.0 \\
\hline Sweden & No medical treatment is required at this age & 61.6 \\
\hline The United Kingdom & No medical treatment is required at this age & 48.0 \\
\hline
\end{tabular}

Most important reason to test Tom (6 months) $(\mathrm{n}=408)$

France $\quad$ To relieve his parents uncertainty 88.6

Germany $\quad$ To relieve his parents uncertainty 94.9

The Netherlands $\quad$ To relieve his parents uncertainty 86.8

Sweden $\quad$ To relieve his parents uncertainty 78.5

The United Kingdom To relieve his parents uncertainty $\quad 86.3$

Most important reason not to test Tom (6 months) $(\mathrm{n}=750)$

$\begin{array}{lll}\text { France } & \text { No medical treatment is required at this age } & 76.4 \\ \text { Germany } & \text { No medical treatment is required at this age } & 73.6\end{array}$

The Netherlands The child is not old enough to understand $\quad 35.9$

$\begin{array}{ll}\text { the medical implications } & \\ \text { Sweden } & \text { No medical treatment is required at this age }\end{array}$

The United Kingdom No medical treatment is required at this age $\quad$ No

Table 6. Most Important Reasons Mentioned by Responding Pediatricians for Testing or Not Testing Catherine Per Country

\begin{tabular}{|c|c|c|}
\hline \multicolumn{2}{|l|}{ Pediatricians } & $\%$ \\
\hline \multicolumn{3}{|c|}{ Most important reason to test Catherine $(8$ years) $(\mathrm{n}=539)$} \\
\hline France & To relieve her parents uncertainty & 74.5 \\
\hline Germany & To relieve her parents uncertainty & 93.0 \\
\hline The Netherlands & To relieve her parents uncertainty & 80.5 \\
\hline Sweden & To relieve her parents uncertainty & 86.0 \\
\hline The United Kingdom & To relieve her parents uncertainty & 89.6 \\
\hline \multicolumn{3}{|c|}{ Most important reason not to test Catherine $(8$ years $)(\mathrm{n}=374)$} \\
\hline France & No medical treatment is required at this age & 55.9 \\
\hline Germany & No medical treatment is required at this age & 44.4 \\
\hline The Netherlands & $\begin{array}{l}\text { The child is not old enough to understand } \\
\text { the medical implications }\end{array}$ & 50.5 \\
\hline Sweden & No medical treatment is required at this age & 46.3 \\
\hline The United Kingdom & $\begin{array}{l}\text { The child is not old enough to understand } \\
\text { the medical implications }\end{array}$ & 56.0 \\
\hline
\end{tabular}

